\title{
Communication Models for Doctor-Patient Relationships
}

\author{
Enrico Aitini • Giancarlo Martignoni • \\ Roberto Labianca $\cdot$ On behalf of the Italian Group for the \\ study of Digestive Tract Cancer (GISCAD)
}

Published online: 6 February 2014

(C) Springer Science+Business Media New York 2014

\section{Introduction}

Progress in medical science, technology and the multidisciplinary approach over the last half century has made it possible for people to live longer and to remain in good physical condition [1]. However, these benefits are sometimes only physical. Many studies have demonstrated that although patients are grateful for restored physical health, they have suffered psychologically from the lack of direct contact with their doctor which has been replaced by an anonymous team of specialists and machines. The old style doctor-patient relationship has been discarded; the patient is no longer a whole person but has become a list of scan and test results. Is it any wonder that patients feel that their doctor is not really interested in them as people [2-4].

In general, medical training does not include or barely touches on the importance of communication in the doctorpatient relationship focusing instead on the physical illness and not the patient $[5,6]$.

The communicative relationship between doctor and patient is inevitably conditioned by numerous variables such as the time and space available, the ability and psychological willingness of the doctor to face bad news for the patient and the patient's ability to take part in a psychologically intense meeting.

The relationship is further conditioned by the medical discipline involved, for example intensive care, paediatrics, oncology, ophthalmology, surgery, dermatology, palliative

\author{
E. Aitini $(\bowtie)$ \\ Medical Oncology Department, Mantua, Italy \\ e-mail: enrico.aitini@hotmail.com \\ G. Martignoni \\ Casa di Cura Ambrosiana, Milan, Italy \\ R. Labianca \\ Medical Oncology Department, Bergamo, Italy
}

care, to name just a few of the specialist disciplines which all represent different experiences for the patient, different diagnostic and therapeutic interventions which often are diametrically opposed and which have a notable influence on the doctor-patient relationship and the method of communication.

Unfortunately, the so called spending review has and will further reduce human resources which translates into the doctor having less time to dedicate to the fundamental moments of treatment such as listening, understanding and having a dialogue with the patient.

\section{Discussion}

This discussion on the doctor-patient relationship, which has been going on for several years, has also attracted the attention of other disciplines such as mathematics, engineering, physics and linguistics. In trying to understand the difficulties which may arise during communication, apart from time restrictions, and consequently affect the doctor-patient relationship, it may be useful to review some of the fundamental milestones reached during the second half of the last century and which still today define the interpersonal communication models predominant in the Western society. We should keep in mind that these methods are based on mathematical and physical models which apparently have nothing to do with the human context of the doctor-patient relationship. However, the development of these theories still today forms the basis of a positive and constructive doctor-patient relationship.

In fact, some years after the end of the Second World War II, American mathematical engineers Claude Elwood Shannon and Warren Weaver developed a mathematical model for communication.

Although this was mainly developed for the technological sector, some elements have found applications in psychology and linguistics. This theory, formulated in 1948 (further 
developed in 1963), is the basis of what is considered the first communicative model of modern times and identified the bidirectionality of communication as opposed to information which is only monodirectional $[7,8]$.

Some years later, Roman Jakobson, a Russian linguist and semiologist and a naturalized American citizen, in his analysis of language highlighted the different features in any discourse by breaking down the functions of the language between sender and receiver into context, message, channel and code. In fact, the doctor must be able to communicate with the patient on his level; in other words, they must be on the same wave length and use the same language (code) in order for communication to take place [9].

In 1965, another particularly important step was taken by Paul Watzlawick in understanding the interpersonal relationships between individuals. He was one of the most influential figures at the Mental Research Institute in Palo Alto, California. Watzlawick was an Austrian-American family therapist, psychologist, communications theorist and philosopher who developed further new concepts relating to communication. He affirmed, among other things, that it is impossible not to communicate. This axion underlines this aspect and the relational and social nature of communication: even isolating oneself, refusing to answer, silence and not reacting, are all forms of communication which are received and understood by others in a very precise way. There is therefore no type of behaviour which is not communicative. Therefore, it follows that the doctor cannot hide from the patient; he or she cannot escape or avoid a dialogue [10,11].

Communication has a content and a relationship aspect. The relationship aspect is HOW it is said non-verbally, and the content is WHAT is actually said verbally. The relationship messages are always the most important elements in communication. Both the sender and the receiver of information interpret their own behaviour during communication merely as a reaction to the other's behaviour.

Today, these concepts are more pertinent than ever given that for some years now, in spite of the dominant and rampant use of technology, besides identifying the purely clinical needs of a patient, the doctor's attention does not only focus on communication and the doctor-patient relationship but also on social, ethical and spiritual aspects and on what can only be defined as "the biography" of the patient. This aspect is particularly relevant in oncology where the temporal dimension of the illness imposes a relationship which accompanies the patient through all the phases of treatment and which becomes even more intense and committed during the critical stages when a multitude of aspects which are not only medical but can relate to family or psychological and social problems or adapting to stress and the changing clinical nature of the illness.

\section{Conclusions and Recommendations}

All stages of the illness present difficult problems from a communication point of view. The patient must face the anguish of the diagnosis of a serious illness and the uncertainty of the outcome knowing however that in any case, he or she has a long, difficult and stressful road ahead to travel.

There are no pre-packaged answers for establishing a good communicative doctor-patient relationship. It has to be developed based on each individual patient and the physical and psychological implications and consequences the illness can have on the patient's life.

The doctor faces the same difficulties, especially one who has developed attention and sensitivity in communicating bad news. As mentioned at the beginning of this article, the doctor must consider the cultural context which has developed over the last couple of decades in the world we live in where communication takes place through electronic devices, where people have forgotten how to write a letter and where suffering and death have become all too common to attract our attention beyond the initial moment [12].

\section{References}

1. Kesson EM, Allardice GM, George WD, Burns HJ, Morrison DS (2012) Effects of multidisciplinary team working on breast cancer survival: retrospective, comparative, interventional cohort study. BMJ 26:344

2. Fallowfield L, Jenkins V (2004) Communicating sad, bad, and difficult news in medicine. Lancet 24:312-319

3. Aitini E, Aleotti P (2006) Breaking bad news in oncology: like a walk in the twilight? Ann Oncol 17:359-360

4. Aitini E (2012) Breaking bad news in onco-hematology: new hope, new words? Leuk Lymphoma 53:328-329

5. Back AL, Arnold RM, Baile WF (2009) What makes education in communication transformative. J Cancer Educ 24:160-162

6. Aitini E (2012) Training young oncologists in doctor-patient relationships. J Cancer Educ 27(1):186-187

7. Shannon C (1948) A mathematical theory of communication. Bell Syst Tech J 27:379-423, 623-656

8. Weaver W, Shannon C (1963) The mathematical theory of communication. Univ. of Illinois Press. ISBN 0-252-72548-4

9. Jacobson R (1961) Linguistics and communications theory. Am Math Soc 2:570-579

10. Watzlawick P (1964) An anthropology of human communication. Science and Behaviour Books, Palo Alto

11. Watzlawick P, Beavin JH, Jackson DD (1967) Pragmatics of human communication. Norton and Co, New York

12. Working Party of the Royal College of Physicians (2005) Doctors in society. Medical professionalism in a changing world. Clin Med 5: S5-S40 